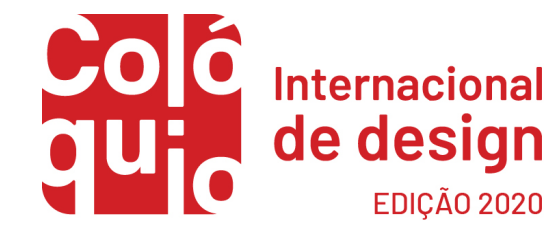

\title{
Design: entre ciência, técnica e arte
}

Sérgio Luciano da Silva;

Rita Aparecida da Conceição Ribeiro

resumo:

O presente artigo parte de algumas das conexões entre ciência, técnica e arte em busca de compreensão do lugar ontológico que ocupa o design em relação a esses campos. Apoiados nas reflexões dos teóricos do design, Tomás Maldonado, Rafael Cardoso, Beat Schneider e Gui Bonsiepe, cotejamos suas posições com a proposta do filósofo Vilém Flusser, de pensar o design enquanto uma ponte entre ciência e arte. $O$ resultado vai ao encontro do entendimento de que o design, enquanto um campo complexo e multidisciplinar, cobra reflexão e responsabilidade de assumirmos a relevância de suas atribuições.

palavras-chave:

Teoria e crítica do design; filosofia; ciência; técnica; arte 
Quando se trata de investigar campos que não se encontram delimitados ou com fronteiras móveis, existem pelo menos duas espécies de dificuldades com as quais precisamos lidar na contemporaneidade. Uma, inerente à fragmentação que enfrentamos no âmbito geral da cultura e do saber, que se estabelece de forma acentuada desde o advento da modernidade. Outra, consequência da hierarquização do conhecimento, derivada em certa medida do platonismo, e que afeta diversas áreas, mas diretamente duas de nosso interesse, design e arte. Essas limitações, próprias dos nossos tempos, são a base para pensarmos, neste artigo ${ }^{1}$, acerca da condição do design enquanto um campo que se coloca estratégica e conceitualmente entre ciência, técnica e arte.

\section{A complexidade das relações entre ciência, técnica e tecnologia}

O teórico e designer Tomás Maldonado se apresenta como um dos críticos e interlocutores importantes desse tema, pois une seus argumentos provenientes de conhecimentos no design e na $\operatorname{arte}^{2}$ com um interesse na filosofia da ciência e da técnica, questionando a tradição idealista e o platonismo. Conforme ele afirma no capítulo Pensar a técnica hoje, do livro Cultura, sociedade e técnica:

Vivemos atualmente em um momento particularmente inovador da longa (e atribulada) história da reflexão sobre a técnica. Constata-se, nas últimas décadas, uma tendência cada vez maior de afastamento daquelas interpretações com viés idealista, que sempre dificultaram as tentativas de se fazer reflexão sobre a técnica.

[...] Basta pensar, por exemplo, na contribuição de E. Zschimmer (1914) e F. Dessauer (1927 e 1959), dois engenheiros-cientistas-filósofos, de filiação hegeliana e kantiana, respectivamente. [...] esses estudiosos estavam convencidos de que as respostas às questões levantadas pela técnica deveriam ser buscadas dentro da própria técnica. A técnica seria uma realidade autônoma, um sistema fechado, que se desenvolve e se autoexplicaria sem ter de recorrer a fatores exógenos. Poder-se-ia dizer - utilizando um termo agora muito na moda - que a técnica é autopoiética. (MALDONADO, 2012, p.153)

Três pontos interligados nessa citação devem ser destacados. Primeiro, a crítica de Maldonado está dirigida principalmente às interpretações, que se apoiam no idealismo e no platonismo. Segundo, a delimitação da forma mais atual do idealismo está vinculada ao conceito de autopoiese ou autoprodução. Terceiro (promovendo a conexão dos dois primeiros pontos), este autor faz uma clara remissão dessa concepção de técnica ao ideário platônico, ao relacioná-la com "realidade autônoma" e "catálogo ideal das formas preexistentes".

A crítica direta de Maldonado à posição platônica é evidente, mas gera dúvidas e, portanto, devemos fazer duas ressalvas. A primeira é que, na antiguidade, o conceito de póiesis, na sua especificação de existência espontânea, é autoprodução e está intrinsecamente associado à natureza (phýsis) (SILVA, 2019, p. 54-56). Mas o mesmo não ocorre na sua especificação enquanto epistéme ou tékhne (SILVA, 2019, p. 58-61). No entanto, seguindo as palavras de Maldonado que fala de "autopoiética", afirmando ser um termo da moda, podemos supor que talvez ele se refira à "autopoiese", palavra cunhada pelo biólogo e epistemólogo Humberto Maturana, na década de 1970, para caracterizar a capacidade dos seres vivos de produzirem a si próprios e que ficou em evidência com os debates em torno da relevância dos sistemas ${ }^{3}$ na compreensão dos fenômenos biológicos.

\footnotetext{
1 As reflexões do presente escrito exploram algumas das análises elaboradas em nossa tese de doutorado (SILVA, 2019), compondo naquela investigação uma introdução ao tema das relações entre design e arte.

${ }^{2}$ Maldonado formou-se pela Academia de Belas Artes de Buenos Aires em 1939 e participou do movimento de Arte Concreta da Argentina entre os anos de 1943 e 1954, antes de se tornar professor de design e reitor na Alemanha, na escola de Ulm. (MALDONADO, 2012)

${ }^{3}$ Conforme afirmam Humberto Maturana e Francisco Varela no livro De máquinas y seres vivos: autopoiesis, la organización de lo vivo, sobre a delimitação do conceito de autopoiese: "A compreensão do caráter sistêmico dos fenômenos que envolvem a vivência possibilitada pela teoria da autopoiese permite explicar a origem dos
} 
Apesar do neologismo autopoiese também remeter à phýsis grega, tanto no conceito quanto na etimologia e raiz da palavra poiese, se Maldonado está apenas se apropriando de sua designação contemporânea relacionada à biologia e aplicando-a em uma concepção de técnica entendida como endógena, a ressalva pode ser mitigada.

A segunda ressalva diz respeito à inclusão do nome de Aristóteles, alinhando-o com o pensamento platônico, pensamento este que também não é idealista ${ }^{4}$. Aristóteles se opõe frontalmente a um mundo de formas ideais preexistentes, ou a um "catálogo". Essa é uma das posições fundamentais de Aristóteles, que o põe historicamente como o primeiro a discordar de Platão e com argumentos suficientes para justificar nossa escolha de colocá-lo no centro da discussão sobre a crítica a uma hierarquia do conhecimento (SILVA, 2019). No entanto, essa restrição não invalida a posição também crítica de Maldonado em relação a uma concepção de técnica entendida como "um sistema fechado". Mas, é importante também atentar que, mesmo nas concepções de tendência "platônica" com "realidades autônomas", a técnica, compreendida como um campo separado da ciência, está cada vez mais atrelada e hierarquicamente submetida a uma teoria que a fundamenta. Ou seja, a questão é realmente complexa e esse vínculo e dependência da técnica em relação à ciência se mostra claramente na sintética e reveladora definição de tecnologia do epistemólogo Alexandre Koyré: "fazer a teoria da prática” (KOYRE, 1991, p. 267).

\section{A integração de fenômenos em campos distintos}

Além de Maldonado, identificamos a disposição de outros pesquisadores em buscar elementos comuns e a integração de fenômenos em campos distintos, na forma de novas teorias ou princípios organizadores, alguns defendendo somente as conexões de seus objetos de estudo e outros apostando em um caráter holístico ou totalizante de seus fundamentos. Analisemos como esse processo vem ocorrendo.

Partindo do pressuposto de que o círculo da epistemologia incorpora ciência e técnica como seus objetos de estudo, selecionamos um grupo de epistemólogos que se tornaram referência para a compreensão das relações dessas duas áreas, subsidiando nossa análise das posições de Tomás Maldonado, Gui Bonsiepe, Beat Schneider, Rafael Cardoso e Vilém Flusser, e contextualizando ciência, técnica e arte com o design. A história da ciência é fundamental para a epistemologia, e o século XX é prolífico em obras como As bases metafísicas da ciência moderna de Edwin A. Burtt (1983) e Estudos de história do pensamento científico de Alexandre Koyré (1982), que se notabilizaram nessa área. O conhecimento acumulado a partir desses historiadores da ciência influenciou mais de uma geração de pesquisadores como Arthur Koestler (1989) e Thomas S. Kuhn (1987), contribuindo inclusive para os célebres debates desse último contra Karl Popper (1972, 1975, 1993) e suas posições. Seus estudos compõem um quadro rico e heterogêneo, calcado na história dessas ciências e de seus desdobramentos para a técnica, demonstrando a construção de relações e avanços pragmáticos já centenários. Tais relações entre as teorias e as suas aplicações interessam a vários campos, inclusive ao design.

Os trabalhos de Tomás Maldonado unem esses temas e autores explorando teoria, história da ciência e da técnica na busca por compreensão de aspectos intrínsecos ao design. É o que se pode constatar em Os óculos levados a sério, onde os avanços na estrutura da técnica e da funcionalidade derivam dos fundamentos de teorias das ciências naturais:

seres vivos na terra, ou em qualquer parte do cosmo, como o surgimento espontâneo de um ser vivo como entidade discreta assim como ocorre a dinâmica molecular autopoiética como um fenômeno sistêmico." (MATURANA; VARELA, 2003, p. 24) Tradução nossa.

${ }^{4}$ Grosso modo, e de um ponto de vista gnoseológico, o conhecido “Mundo das ideias" de Platão é concebido como a verdadeira realidade. Para Platão tal mundo é real e os objetos que o compõem, as ideias, possuem propriedades constitutivas reais. Por outro lado, o conceito de idealismo da modernidade, apesar do nome, não tem a ver com o mundo das ideias platônico, mas com o entendimento de que os objetos não têm existência real fora de nós, sendo construídos em nossa consciência. Johannes Hessen, em seu livro Teoria do conhecimento (1980), traz uma introdução bastante concisa e clara a essas e outras posições gnoseológicas. 
As lentes abriram o caminho para o desenvolvimento das primeiras lunetas e os primeiros microscópios compostos. Prenunciaram, ainda, o advento da ótica fina e de altíssima precisão, ou seja, daquele conjunto de instrumentos e de aparelhos que serviram de alicerce para a poderosa revolução que nos levou do 'mundo da aproximação ao universo da precisão', para utilizar a feliz expressão de A. Koyré (1961). (MALDONADO, 2012, p. 178).

Neste capítulo exemplar do livro Cultura, sociedade e técnica, Maldonado, discursa não somente como designer, mas também como epistemólogo, e busca explicar a invenção de objetos que incorporam design, como os óculos, rastreando sua origem na história das ciências e da técnica. Com os subsídios teóricos de Alexandre Koyré, argumenta de modo analítico em favor de uma aproximação dessas duas áreas. E do mesmo modo, no capítulo Pensar a técnica hoje, Maldonado reforça a atenção concentrada na atualidade no âmbito da ciência e da técnica, na discussão sobre os seus fundamentos:

Trata-se da velha questão da atualidade ou não das estratégias cognitivas que, desde F. Bacon, propiciaram alcançar formidáveis resultados nos campos da descoberta científica e da inovação tecnológica. Ela permanece no centro do debate entre os filósofos e cientistas. É cada vez menor o número daqueles que atribuem uma validade universal e uma objetividade absoluta, à metodologia da pesquisa tecnocientífica. Outros a colocam em discussão em nome do pluralismo e do relativismo; outros, ainda, levantam a hipótese de uma mediação entre essas duas posições extremas ou, então rejeitam a ambas. É um debate que, no fundo, refere-se aos fundamentos lógicoepistemológicos do empreendimento científico. (MALDONADO, 2012, p. 155)

Apesar de não identificar quais autores estão no centro deste debate, Maldonado assinala uma redução no número de estudiosos que privilegiam conceitos caros à ciência ortodoxa quantitativa, como "validade universal" e "objetividade absoluta". Tal percepção de Maldonado é sintoma de seu posicionamento atento a uma flexibilização de princípios que podem conduzir a uma relativização de elementos rígidos do platonismo. E supomos que seu entendimento da conexão entre ciência e técnica é forte o bastante para levá-lo à fusão desses dois conceitos no neologismo "tecnocientífica". Mas poderíamos também supor um sinal de hierarquia, ou pelo menos de causa e efeito preservado na descrição de Maldonado, ao falar dos "formidáveis resultados" ordenando em primeiro lugar o campo da "descoberta científica" e em segundo o da "inovação tecnológica". Depois de séculos de confiança em tal ordenação, faz parte até do senso comum ${ }^{5}$ considerar ciência em primeiro e técnica em segundo, o que se reflete também na forma como escrevemos. Mas Maldonado tem consciência da complexidade das relações entre ciência e técnica. Tanto que, mais uma vez, no seu capítulo sobre os óculos, destaca a importância de reconsiderarmos a questão:

Novamente se propõe a velha ideia que são os doutos - e não os práticos - os principais protagonistas da inovação tecnológica. Essa ideia está no centro das controvérsias de muitas invenções. Quem foi, por exemplo, o inventor da máquina a vapor: o douto Denis Papin ou o prático Thomas Newcomen? O douto Joseph Black ou o douto-prático James Watt? (MALDONADO, 2012, p. 182)

Acerca dessa polêmica, que Maldonado insere no cerne do tema sobre a causalidade (2012, p. 176-177), e um dos objetos centrais da filosofia desde suas origens, Koyré provavelmente diria que não importa quem foi o autor, se um "douto" ou um "prático", mas que qualquer dos dois protagonistas precisou necessariamente de fundamentação teórica para guiar seu projeto "tecnológico", dado o nível de complexidade deste tipo de invenção. Com relação a Maldonado,

\footnotetext{
${ }^{5}$ Como afirma Koyré em nota do seu consagrado ensaio "Do mundo do 'mais-ou-menos' ao universo da precisão", reverenciado por Maldonado: "O senso comum não é alguma coisa de absolutamente constante: nós não examinamos mais a abóbada celeste. Da mesma forma, o pensamenteo técnico tradicional, as regras dos ofícios, a $\tau \dot{\varepsilon} \chi \vee \eta$ [tékhne] pode absorver - e o fez no decorrer da história - elementos do saber científico." (KOYRÉ, 1991, p. 287)
} 
podemos afirmar que dessa complexidade pode derivar o "pluralismo", de que ele nos fala, associando-o a busca por elementos comuns e relações entre os campos (rotulada sob certas circunstâncias de interdisciplinaridade), tão característica de nossa época e que pode ser incorporada também aos objetivos teóricos do design. Em suas palavras:

Torna-se cada vez mais claro que somente será possível desenvolver uma história da técnica mais próxima aos nossos problemas atuais com a colaboração dos filósofos, historiadores, etnólogos, engenheiros, economistas, psicólogos e sociólogos. [...] É improvável que se possa estudar a técnica sem recorrer a tal cooperação interdisciplinar. Cada estudioso deveria procurar assimilar o saber oriundo de outras disciplinas, mesmo permanecendo fiel às particularidades do seu próprio campo de pesquisa. Esse saber seria capaz de tornar o seu trabalho menos parcial e, portanto, mais verdadeiro e concreto. (MALDONADO, 2012, p. 159).

O pensamento sistêmico defendido por, entre outros, Rafael Cardoso, historiador da arte e do design, é mais uma prova do interesse de pesquisadores do design em avançar na seara das conexões entre os campos. Partindo da mesma linhagem de epistemólogos com a qual Maldonado dialoga, Cardoso explora um caminho diverso e se insurge contra uma concepção do design enquanto ciência de cunho analítico:

\begin{abstract}
A maior e mais importante contribuição que o design tem a fazer para equacionar os desafios do nosso mundo complexo é o pensamento sistêmico. Poucas áreas estão habituadas a considerar os problemas de modo tão integrado e comunicante. $\mathrm{O}$ procedimento metodológico básico em qualquer atividade científica é recortar e fracionar o problema para constituir uma situação experimental passível de averiguação. Esse método funciona extremamente bem para uma série de análises, mas é de pouca valia para lidar com a elaboração de grandes sistemas complexos, sua manutenção e planejamento. Quando os problemas atravessam saberes e disciplinas, por exemplo, é limitado o que cada uma delas pode fazer para resolver o todo. Assim como outras áreas projetuais - em especial, a engenharia e a arquitetura - o design parte de uma abordagem diferente. Em vez de fracionar o problema para reduzir as variáveis, o designer visa gerar alternativas, cada uma das quais tende a ser única e totalizante. Sua meta é viabilizar uma solução, e não garantir a reprodutibilidade do experimento - construção e não desconstrução, "factibilidade" e não "falseabilidade", partidos e funções em vez de conjeturas e refutações. (CARDOSO, 2016, p. 243-244)
\end{abstract}

Na citação anterior, a desvinculação de Cardoso de uma epistemologia apropriada às ciências naturais, segundo ele, não adequada ao design, não apresenta um autor explícito (como o faz Maldonado com Koyré), talvez por uma questão de estilo. Mas é possível supor que Cardoso está se referindo a Popper ao fazer uso dos termos "falseabilidade" e "conjeturas e refutações", respectivamente um conceito e um título de uma das obras mais influentes desse epistemólogo. E, portanto, ao propor a síntese e a factibilidade ao invés da análise e falseabilidade, reitera sua posição de afastar o design de uma concepção de ciência, stricto sensu. Tal posição faz sentido se o design recorre frequentemente ao argumento de que é um campo projetual com fronteiras pouco definidas e que trabalha transversalmente em conjunto com outras disciplinas.

O designer e historiador do design, Beat Schneider, a propósito dessas fronteiras e da complexidade dos campos, também recomenda a interdisciplinaridade como modo de abordar questões:

O pensamento e a reflexão são uma parte do processo de criação. Deles pode partir a teoria - no sentido de uma reflexividade que problematiza o processo de criação. Hoje essa reflexividade faz-se mais necessária do que nunca, pois tanto a prática social e técnica quanto a prática do design tornaram-se muito complexas. O design precisa de uma teoria que corresponda à sua complexidade. Essa complexidade do design está em seu objeto e em sua constituição interdisciplinar e transdisciplinar. Uma rede de muitas 
disciplinas científicas, das áreas das ciências humanas, sociais e da engenharia, disciplinas da indústria, comércio, administração e cultura, bem como a complexa multiplicidade de usuários, participam do processo de design e da resolução comum de tarefas. (SCHNEIDER, 2010, p. 266)

Compartilhando com Cardoso a essência projetual do design, Schneider, no entanto, considera este campo como ciência. Depois de haver nomeado o "design como ciência jovem" (SCHNEIDER, 2010, p. 193), este autor discorre sobre as atividades deste campo: "Sua tarefa é contribuir enquanto ciência para tornar nosso complexo mundo visível e legível. Ela se situa no contexto normativo da tradição iluminista da alfabetização e da democratização do saber e do conhecimento." (SCHNEIDER, 2010, p. 266)

O teórico e designer Gui Bonsiepe também resguarda o mesmo âmbito projetual que Cardoso e Schneider e almeja uma interação entre design, entendido como território de projeto, e ciência enquanto campo de conhecimento:

Enquanto as ciências enxergam o mundo sob a perspectiva da cognição, as disciplinas de design o enxergam sob a perspectiva do projeto. Essas duas perspectivas diferentes que, oxalá, no futuro, acabem se fundindo. Estou convencido de que, no futuro, haverá uma interação frutífera entre o mundo das ciências e o mundo do projeto que, hoje, se dá, no máximo, esporadicamente. (BONSIEPE, 2011, p. 19)

Mas é importante atentar que, tal interação e até fusão de perspectivas, na concepção de Bonsiepe, não significa transformar o design em ciência:

A atitude de colocar o projeto relacionado com as ciências não deve ser interpretada como um postulado por um design científico ou para transformar design em ciência. Seria grotesco querer projetar um cinzeiro baseando-se em conhecimentos científicos. Deveria ser criada uma correspondência entre complexidade temática e metodologia. $\mathrm{O}$ design deve recorrer a conhecimentos científicos quando a temática o exige. Por exemplo, quando se quer projetar uma nova embalagem para leite que minimize os impactos ecológicos (ecological footprints). (BONSIEPE, 2011, p. 19)

A posição assumida por Bonsiepe tem aspectos que nos atraem, pois também não consideramos um problema recorrer a conhecimentos científicos de outras áreas. Pelo contrário, esse procedimento, de não reinventar a roda, é cada vez mais comum em disciplinas que ampliam sua atuação em novos territórios. E, no nosso entendimento, não ser ciência não implica no design ser excluído dos territórios do conhecimento. $\mathrm{O}$ atributo da cognição e da construção do saber não é exclusividade da ciência. Portanto, acreditamos que quando Bonsiepe afirma que os dois campos enxergam o mundo com perspectivas diferentes, ele não estabelece categorias estanques, o que para nós é essencial na medida em que não compreendemos o design isolado ou enrijecido em suas fronteiras com outras áreas, sejam elas científicas, técnicas ou artísticas. Diríamos que o expressivo uso, por Bonsiepe, da palavra "enxergar" une ciência e design em atividades de características comuns, em que a "perspectiva" apenas direciona a visão para aspectos distintos de uma mesma realidade. Se for assim, o liame proposto por esse autor para as concepções de ciência e design retoma, de forma elegante, o legado conceitual de conhecimento especulativo, em sua origem na antiguidade grega, em que teoria $(\theta \varepsilon \omega \rho i ́ \alpha)$ denota ação de ver, de observar, contemplar, examinar e investigar. E sua relação com o olhar, aproxima-a de oida (oĩ $\delta \alpha$ ) significando, ao mesmo tempo, ver e compreender (SILVA, 2019, p. 61).

\section{Uma "ponte" entre ciência e arte}

Nesse sentido, o filósofo Vilém Flusser tem o papel relevante de elo a esse grupo de autores que, de algum modo, exploram as reflexões filosóficas em favor da compreensão dos estatutos do design. Este pensador se interessa pela separação entre ciência, técnica e arte, que, segundo ele, ocorre "pelo menos" a partir da Renascença. Sua proposta para atenuar essa "separação desastrosa" ou "brecha", 
entendida com "insustentável", é a de pensar o campo do design como uma "ponte" entre ciência, técnica e arte. Nas suas palavras:

A palavra design entrou nessa brecha como uma espécie de ponte entre esses dois mundos. E isso foi possível porque essa palavra exprime a conexão interna entre técnica e arte. E por isso design significa aproximadamente aquele lugar em que arte e técnica (e, consequentemente, pensamentos, valorativo e científico) $\left[^{6}\right]$ caminham juntas, com pesos equivalentes, tornando possível uma nova forma de cultura. (FLUSSER, 2007, p. 183-184)

Da forma como compreendemos, essa "brecha" se inicia em um período bem anterior ao indicado por Flusser, com Platão, em uma teoria acerca da realidade que cinde o conhecimento em áreas e com tal teoria também surge a hierarquização do conhecimento que defende a existência de áreas mais próximas da verdade do que outras. Independentemente do momento histórico em que essa cisão ocorreu, se Flusser não assume, com todas as letras, a existência na atualidade de uma hierarquização entre áreas do saber, tal consciência se manifesta em poucas palavras, quando ele qualifica o design para estabelecer a arte e a técnica "com pesos equivalentes". Essa visão peculiar difere, por exemplo, do pensamento de Cardoso, que não considera necessária a ação do design para instituir a equidade entre a arte e outros campos: "Arte é um meio de acesso ao desconhecido, em pé de igualdade com a ciência, a filosofia, a religião [...]" (CARDOSO, 2016, p. 246).

E quando Flusser emprega o termo "conexão interna" pode parecer que ele compreende design e arte como indistintos. No entanto, as palavras "caminham juntas", indicam que seguem uma mesma direção, mas não de indistinção entre áreas. Isso se torna mais claro com o seu conceito de "ponte", pois a indistinção não carece desse artifício de ligação. Assim, paradoxalmente, o ponto de vista de Flusser, um filósofo que procura ligar design e arte, não necessariamente se opõe à posição de Bonsiepe, um designer que pensa a filosofia para distinguir design e arte. ${ }^{7}$ Além disso, podemos afirmar que ambos concordam com outra conexão: aquela entre design e ciência/técnica. Lembremos o que Bonsiepe diz a esse respeito: "Estou convencido de que, no futuro, haverá uma interação frutífera entre mundo das ciências e o mundo do projeto que, hoje, se dá, no máximo, esporadicamente." (BONSIEPE, 2011, p. 19). Neste sentido, podemos afirmar que novamente Bonsiepe tem uma compreensão alinhada com a proposta flusseriana:

Não se pode mais restringir o conceito de projeto às disciplinas projetuais como ocorre na arquitetura, no design industrial e no design de comunicação visual, pois nas disciplinas científicas também há projeto. Quando um grupo de engenheiros agrônomos desenvolveu uma nova merenda, com base na semente de algaroba acrescida de sais minerais e vitaminas básicas para escolares, realizou um claro exemplo de projeto.

Portanto, já registramos uma zona de contato entre ciências e projeto, embora ainda não tenhamos, até o momento, uma teoria projetual que abarque todas as manifestações projetuais, como na engenharia genética que, sem dúvida alguma, deve ser considerada uma disciplina projetual científica. (BONSIEPE, 2011, p. 19)

$\mathrm{Na}$ citação anterior, nossa atenção se concentra na semelhança entre a ideia de "zona de contato" em Bonsiepe e a de "ponte" em Flusser. As possibilidades que esses dois conceitos liberam para o design e outros campos atuarem como conectores entre áreas do conhecimento são substanciais e promissoras. Bonsiepe expõe sua ideia sobre uma "teoria projetual" como um vínculo

\footnotetext{
${ }^{6}$ Devemos estar atentos em relação à forma de Flusser conduzir seus raciocínios e expressar suas ideias. Na citação ele não se preocupa em explicitar a diferença entre ciência e técnica, permutando o uso desses conceitos. Essa também é uma postura adotada por Platão, em alguns de seus diálogos, em relação à tékhne e à espistéme.

${ }^{7}$ Conforme Bonsiepe: "Há muito tempo dispomos de conceitos filosóficos para fazer distinção entre arte e design. Classificar design em categorias artísticas só pode ser explicado por critérios da política de distribuição de verbas nas universidades". (Bonsiepe, 2011, p. 181)
} 
entre diversas áreas. Atuando como epistemólogo, propõe, de modo perspicaz, uma disciplina que, do modo como entendemos, exerceria (enquanto um substrato metafísico) suporte à etapa de projeto, do qual os campos implicados em práticas projetivas poderiam usufruir. De modo similar à visão de Bonsiepe, a ideia de Flusser, no entanto, nos atrai mais pelos diversos desdobramentos que pudemos identificar e que tem proximidade com nossa abordagem. Apesar da semelhança conceitual, diferentemente da zona de contato, na ideia de ponte, o design é a própria ponte. A ponte liga ciência de um lado e arte do outro, o que é um modo de nos esquivarmos da cisão entre áreas do saber. A ponte também permite reconsiderar se o problema da hierarquização do conhecimento, advinda da cisão em áreas, pode ser eventualmente mitigado ou até eliminado. A possibilidade de quebra ou supressão parcial da hierarquia aponta um caminho para avançarmos na reflexão sobre o estatuto ontológico do design e da arte.

\section{Considerações finais}

Nesse sentido, acreditamos que o design pode atuar, não construindo pontes, mas efetivamente sendo a ponte que conecta áreas. Com isso, também é possível avançarmos em direção a domínios até então impensados, como o da natureza, como propõe Flusser (2007), em seu âmbito biológico. Com todos os riscos que Flusser aponta quando trata o tema da ação do design sobre a natureza, e devemos atentar para eles, este campo opera uma ampliação da realidade: em outras palavras, uma operação ontológica (SILVA, 2019). Na verdade, se nos mantemos dentro da metáfora de Flusser de que o design é uma ponte, ela deve ser sólida e ampla o suficiente para os designers poderem se movimentar tanto na direção da arte quanto na da ciência, sem que essa estrutura de ligação se abale, e preservando seus fundamentos.

Outra pergunta fundamental, desdobramento da saída flusseriana, é: com quais elementos tal ponte se concretiza? Em investigações anteriores propusemos, entre outros princípios de natureza ontológica, os conceitos aristotélicos de mímesis e de fim em si mesmo, devidamente reelaborados para a atualidade, fundamentos que contribuem para estruturar tal "ponte" entre diversas áreas (SILVA; SILVA, 2013, SILVA; RIBEIRO, 2013 e SILVA, 2019).

No entanto, talvez uma das propostas mais radicais de Flusser tenha a ver com sua decisão de colocar o design no centro daquilo que ele denomina "Revolução Industrial 'biológica"” e se perguntar sobre a capacidade do designer de elaborar soluções para os efeitos noviços de suas criações:

Esse é um problema de design: como devem ser as máquinas, para que seu contragolpe não nos cause dor? Ou melhor: como devem ser essas máquinas para que o contragolpe nos faça bem? Como deverão ser os chacais de pedra para que não nos esfarrapem e para que nós mesmos não nos comportemos como chacais? Naturalmente podemos projetá-los de modo a que nos lambam, em vez de morder-nos. Mas queremos realmente ser lambidos? São questões difíceis, porque ninguém sabe de fato como quer ser. No entanto, devemos debater essas questões antes de começarmos a projetar chacais de pedra (ou talvez clones de invertebrados ou quimeras de bactérias). E essas questões são ainda mais interessantes do que qualquer chacal de pedra ou qualquer futuro super-humano. Será que o designer estará preparado para colocá-las? (FLUSSER, 2007, p. 49-50) negrito nosso.

É notável que Flusser, um filósofo, transfira, pelo menos em parte, a responsabilidade de reflexão sobre os fins do homem e da natureza, da esfera da filosofia e da ciência, para o âmbito do design, incluindo o designer no "debate" dessas questões, que devem, segundo ele e com razão, preceder aos projetos. Talvez o deslocamento ou rearranjo de compromissos esteja associado ao conceito de projeto com o qual Flusser abarca também o mundo biológico em suas "quimeras de bactérias". Seja como for, se reconhecemos o design como capaz de contribuir nessa esfera da realidade, devemos também assumir a responsabilidade que é acrescida ao papel deste campo. 
Design: between science, technique and art

Abstract: This paper starts from some of the connections between science, technique and art in search of understanding the ontological place that design occupies in relation to these fields. Supported by the reflections of design theorists, Tomás Maldonado, Rafael Cardoso, Beat Schneider and Gui Bonsiepe, we compared their positions with the proposal of the philosopher Vilém Flusser, to think of design as a bridge between science and art. The result is in line with the understanding that design, as a complex and multidisciplinary field, demands reflection and responsibility to assume the relevance of its attributions.

Keywords: Theory and critique of design; philosophy; science; technical; art

\section{Referências}

BONSIEPE, Gui. Design, cultura e sociedade. São Paulo: Blucher, 2011.

BURTT, Edwin A. As bases metafísicas da ciência moderna. Brasília: UnB, 1983.

CARDOSO, Rafael. Design para um mundo complexo. São Paulo: Ubu Editora, 2016.

FLUSSER, Vilém. $\mathbf{O}$ mundo codificado: por uma filosofia do design e da comunicação. Tradução Raquel Abi-Sâmara. São Paulo: Cosac \& Naify, 2007.

HESSEN, Johannes. Teoria do conhecimento. Tradução Dr. António Correia. Coimbra: Arménio Amado Editora, 7a edição, 1980.

KOESTLER, Arthur. 0 homem e o universo: como a concepção do universo se modificou, através dos tempos. Tradução Alberto Denis. São Paulo: Ibrasa, $2^{\mathrm{a}}$ edição, 1989.

KOYRÉ, Alexandre. Estudos de história do pensamento científico. Brasília: Forense Universitária; Editora Universidade de Brasilia, 1982.

KOYRÉ, Alexandre. Estudos de história do pensamento filosófico. Brasília: Forense Universitária; Editora Universidade de Brasília, 1991.

KUHN, Thomas S. A estrutura das revoluções científicas. São Paulo: Perspectiva, $2^{\mathrm{a}}$ edição, 1987.

MALDONADO, Tomás. Cultura, sociedade e técnica. São Paulo: Blucher, 2012.

MATURANA, Humberto; VARELA, Francisco. De máquinas y seres vivos: autopoiesis, la organización de lo vivo. $1^{\text {a }}$ edição, Buenos Aires: Lumen, 2003.

POPPER, Karl R. Conjecturas y refutaciones: el desarrollo del conocimiento científico. Barcelona: Paidos, 1972.

POPPER, Karl R. Conhecimento objetivo: uma abordagem evolucionária. Belo Horizonte: Itatiaia; São Paulo: Editora Universidade de São Paulo, 1975.

POPPER, Karl R. A lógica da pesquisa científica. São Paulo: Cultrix, 1993.

SCHNEIDER, Beat. Design - uma introdução: o design no contexto social, cultural e econômico. São Paulo: Blücher, 2010.

SILVA, Sérgio L.; RIBEIRO, Rita. A. C. As relações entre arte e design: uma análise de discursos subjacentes e de pressupostos de comunicação. Alceu: Revista de Comunicação, Cultura e Política. (Online), Rio e Janeiro, v. 13, p. 116 - 126, 2013. Disponível em: < http://revistaalceu.com.pucrio.br/media/artigo8_26.pdf > Acesso em: 21 jun. 2013. 
SILVA, Sérgio L.; SILVA, Sérgio A. O Conceito aristotélico de mímesis aplicado ao processo criativo em design. Estudos em Design, Rio de Janeiro, v. 21, n.1, p. 1-14, 2013. Disponível em:

<https://estudosemdesign.emnuvens.com.br/design/article/download/107/104> Acesso em: 15 jul. 2020.

SILVA, S. L. Os fundamentos ontológicos das relações entre design e arte. 2019. 224 f. Tese (Doutorado em Design) - Escola de Design, Universidade do Estado de Minas Gerais, Belo Horizonte, 2019. Disponível em: <https://sucupira.capes.gov.br/sucupira/public/consultas/coleta/trabalho Conclusao/viewTrabalhoConclusao.jsf?popup=true\&id_trabalho=7672534>. Acesso em: 03 jul. 2020. 